\title{
Website quality and performance indicators including ratio numbers - A study of German and Danish SME companies
}

\author{
Heiko Thimm ${ }^{\mathrm{a}^{*}}$, Karsten Boye Rasmussen ${ }^{\mathrm{b}}$, Wolfgang Gohout ${ }^{\mathrm{c}}$ \\ a Pforzheim University, School of Engineering, Tiefenbronner, Pforzheim, Germany. \\ Fon: +49 (0)7231/28-6451, Fax: +49 (0)7231/28-7451. \\ b University of Southern Denmark, Department of Marketing \& Management, Campusvey 55, 5230 Odense M, Denmark. \\ Fon: +45 6550 2115, Fax: +45 6615 5129, E-mail: kbr@sam.sdu.dk \\ c Pforzheim University, School of Engineering, Tiefenbronner Str. 65, 75175 Pforzheim, Germany. \\ Fon: +49 (0)7231/28-6597, Fax: +49 (0)7231/28-7597. \\ *Corresponding author's email address: heiko.thimm@hs-pforzheim.de
}

\section{A R T I C LE IN F O}

Received: 25-05-2016

Accepted: 04-07-2016

Available online: 12-07-2016

Keywords:

Company performance indicators;

Correlation analysis;

Small and medium enterprises;

Website quality.

JEL Classification:

C1; C8; M13; M150; 032; 033.

\begin{abstract}
A B S T R A C T
We expect economic benefits from companies with good company websites. However, only little is known about the real effects of good websites on company success. Based on data about 1,000 small and medium-sized European production companies in Germany and Denmark a study is conducted in order to uncover correlations between economic indicators and the quality of company websites. The set of performance indicators for the companies are extracted from the ORBIS company database. The website quality data are obtained through a criteria-based evaluation method. A set of multivariate analyses of the data are performed using the Pearson method and the Spearman method. These analyses also include investigations for the constituent parts of indicators that are ratio numbers. At the country level, it turns out that in some areas the Danish companies outperform the German companies. Also the obtained results show that there exists a correlation between the website quality and the number of employees. A yet insignificant correlation between website quality and the ratio number 'financial gearing' is revealed, too. However, when decomposing 'financial gearing' into its constituent parts, bivariate correlation analyses with the constituent parts lead to highly significant correlations.
\end{abstract}

This is an open access article under the terms of the Creative Commons Attribution License 4.0, which allows use, distribution and reproduction in any medium, provided the original work is properly cited.

DOI: http://dx.doi.org/10.18533/job.v1i6.39 ISSN: 2380-4041 (Print), 2380-405X (Online)

\subsection{Introduction}

Many company websites have been developed based on best practices (Rosenfeld \& Morville, 2002; McIntire, 2008). They typically offer general information about the company such as the history, a mission statement, the product portfolio, partners, and customers. Also, the websites usually offer functions such as functions to request information material, to subscribe to a newsletter, to search in a product catalogue, and to buy from an online shop. The characteristics of today's company websites have been evaluated in several research studies (Chang, Chen, Hsu, \& Kuo, 2012;Gregg \& Walczak, 2010; Ford, Huerta, Diana, Kazley, \& Menachemi, 2013; Hur, Jae Ko, \& Valacich, 2011; Hsiu-Fen, 2007). These studies mainly uncovered common characteristics and differences of websites and website qualities among different companies in different industries. When looking at company websites, one needs to consider the inherent rule of private companies that incurred cost - such as for 
the development and maintenance of a company website - are to be justified by economic benefits eventually. The mainly descriptive website studies, however, provide only little help for understanding the effects of good website quality on economic benefits and, henceforth, the company's economic performance. Thislimited available knowledge has been the starting point of the research described in this article. The objective of this research is to extend today's relatively little amount of research on website quality and company performance (Watkins \& Smith, 2008; Masurel, 2004; Vaughan \& Wu, 2004; Vaughan, 2004)by a thorough statistical investigation. The study is based on empirical data about small and medium sized enterprises (SMEs) in the manufacturing sector in two adjoining European regions in northern Germany and in southern Denmark. The websites of the target group are evaluated considering functional characteristics and aesthetical characteristics. Website quality scores are obtained for the companies by building a formative aggregated website quality index. Typical descriptive statistical analyses of the quality scores are performed, for example, in order to explore difference between German SMEs and Danish SMEs. For a set of carefully selected performance indicators, from the popular ORBIS company database of Bureau van Dijk (Bureau van Dijk, 2015),data are extracted and associated with the website quality scores. In order to uncover correlations between the performance indicators and the website quality, several multivariate analyses of the data are performed. The Pearson method and the Spearman method are used for these analyses. Especially, for indicators that are ratio numbers, it is intended to investigate if correlations exist among the constituent parts of the indicators.

The investigation leads to several main results. A comparison of the website quality at the country level shows that the Danish companies outperform the German companies. The obtained results also provide evidence for the existence of a correlation between the website quality and the number of employees. Furthermore, the study reveals a correlation of an insignificant level between the website quality and the indicator 'financial gearing'. However, further bivariate correlation analysis directed at the constituent parts of the ratio number 'financial gearing' uncovers highly significant correlations. The findings of the study extend the current research literature by empirical evidence for several correlations between performance indicators and website quality that have not been addressed before. Furthermore, the study adds an example that demonstrates how meaningful further insights into correlations can be obtained by decomposing ratio numbers and applying correlation analyses on the constituent parts. A specific example is described in which a not significant statistical link between two indicators is obtained and accordingly further investigated. The further investigation uncovered highly significant correlations between one indicator's constituent parts and the other indicator. Also, the study provides merits to regional development organizations such as business development agencies and policy makers. For example, the findings concerning website quality differences at the country level may inspire promotion initiatives in order to achieve better website quality scores. Furthermore, the evidence provided by the study may influence policy makers to decide for SME specific financial support programs to encourage firm leaders to invest into website improvements.

In the following Section 2, the relevant research literature is reviewed. Then, in Section 3, an overview of the project history is given and the research approach of the study is given. The evaluation method for website quality and the focused company performance indicators are the subjects of Section 4 . Section 5 contains a country comparison of website quality based on the sample data. In Section 6 and Section 7, the statistical investigations are described and the obtained results are discussed. Section 8 contains the conclusions and gives an outlook of future work.

\subsection{Literature review}

The following description of related work is divided in three parts. The first section contains research on measurement criteria and methods to evaluate the quality of company websites. A review of corporate performance indicators is contained in the then following section. Finally, previous research on the linkage between website quality and corporate performance indicators are described. An extensive description of related work in all of these three fields is presented in a university thesis (Schilling, 2015).

\subsection{Research on website quality}

Previous studies on website quality havetargeted the travel sector (Chang, Chen, Hsu, \& Kuo, 2012), the area of electronic commerce (Gregg \& Walczak, 2010), the health sector (Ford, Huerta, Diana, Kazley, \& Menachemi, 2013), the sports sector (Hur, Jae Ko, \& Valacich, 2011)and the book industry (Hsiu-Fen, 2007). Also crosssectorial and cross-industry websites have been the subject of various research projects (Hung-Chang, Yi-Ching, \& Ching-Yi, 2005; Xi, Zhuang, Huang, She, \& Zhang, 2007). Earlier website studies have often used surveydata collection methodology. Especially, to conduct a survey with a 7-point scale for each attribute appears to be a popular approach for gathering quality data (Chang, Chen, Hsu, \& Kuo, 2012; Gregg \& Walczak, 2010; Ford, Huerta, Diana, Kazley, \& Menachemi, 2013; Hur, Jae Ko, \& Valacich, 2011; Hsiu-Fen, 2007; Hung-Chang, Yi-Ching, 
\& Ching-Yi, 2005). Instead of a survey-based approach, Ford et al. (2013) prefer the use of a web crawler in order to obtain a topographical map of the links within a website.

In the following, some selected studies are described in more details. Chang et al. (2012) investigated the linkage between website quality and website user's behavioural intentions. They make use of two perspectives, namely the technical-oriented and the customer-oriented perspective. The technical-oriented perspective serves to get information about information quality and system quality. The customer-oriented perspective is directed at questions about the availability of prompt service, the willingness to help customers, trustworthiness, the provision of targeting email to customers and customers' free personal homepage on the website. Ford et al. (2013) investigated the relationship between the quality of hospitals' public websites and their aggregated patient satisfaction ratings. The researchers analysed 1,952 U.S. hospitals and gathered the quality information by using a web crawler. An overall score of the website was computed from 34 variables. These 34 variables belong to one or several of the following subordinate measurement groups: accessibility, site content, marketing, and adherence to technical standards. Gregg and Walczak (2010) investigated the impact of a website's value on trust, on intention to transact, and on price premiums. To this end, a field survey was conducted in which two online auction listings were considered and 701 experienced Ebay users were surveyed. In order to describe the website quality two sets of questions were established. The first set, information quality, contained three questions directed at the sufficiency, the readability and accuracy of the information. The second set, web design, targeted the issue of whether the listing displays a visually pleasing design and whether the listing has a high quality professional appearance. Xi et al. (2007) conduct a cross-industry analysis, targeting to understand the business objectives of 74 Chinese corporate websites. Their assessment criteria for website quality are based on the approach of Cheung and Huang (2002)who take the following three dimensions into account: functionality, content, and user satisfaction. The websites were examined by trained students. In order to determine the website quality, the average assessment score was calculated for each criterion per industry.

Different approaches for computing an overall website quality score or index from multiple variable inputs are described in the literature. The quality of a website is mostly assessed by simply calculating the mean of all variables or sub dimensions respectively (Chang, Chen, Hsu, \& Kuo, 2012; Hur, Jae Ko, \& Valacich, 2011; HsiuFen, 2007; Hung-Chang, Yi-Ching, \& Ching-Yi, 2005; Xi, Zhuang, Huang, She, \& Zhang, 2007). González and Palacios (2004) evaluate websites making use of a Web Assessment Index based on Hernández, Jiménez, and Martín (2009). The dimensions are cumulated based on subjectively determined weights (González \& Palacios 2004, p. 318; Rasmussen \& Thimm, 2015, p. 89). Kaya and Kahramann (2011) proposed an assessment methodology for website quality based on an integrated fuzzy AHP-ELECTRE approach.

\subsection{Corporate performance indicators}

In general, two broad categories for corporate performance indicators have been suggested by researchers such as Tangen (2003, p. 348), Kaplan and Norton (1992), andTan and Smyrnios (2011). The two categories are referred to as 'financial performance indicators' and 'non-financial performance indicators'. Financial measures mainly reflect results or past performance, whereas non-financial indicators provide information on the future performance or strategic success drivers. The focus of the research described in this article is on financial performance indicators. Therefore, non-financial indicators are not included in the following description of performance indicators.

According to Sierpińska and Jachna (2004, p. 16), the financial analysis is the most significant method for economic analysis and traditionally comprises an analysis of financial reports. The balance sheet, profit and loss account as well as cash flow statement represent parts of the before mentioned financial reports. Miller (2015)described three areas performance ratios can be related to, namely liquidity ratios, ratios regarding the capital structure, and asset ratios. Liquidity ratios address the financial solvency of a company. They allow a statement about the extent to which the company is able to meet payment obligations in a short run and in a long run. Ratios regarding the capital structure of a company reflect to what extent the company is financed by debt. An example would be the equity ratio representing the independency of the company from debt providers. The third group of ratios takes into account the company's assets, measuring the performance by utilization of assets and therefore the bound capital.

Merritt (2015)compares the indicators net income and net sales or net revenue, respectively. It is argued that these two measures can serve as an appropriate representation of company performance. Net income is the profit of a company - the "bottom line in business". Net sales, on the other hand, refers to the "top line" that can be found in the income statement, which means the overall amount of money that is generated by sales. George, Zahra, and Wood (2002)also identified financial performance measures. They use net sales to total assets or 
asset turnover, respectively, to determine the performance of a company relative to its asset input. This measure reflects the ability of a company to use existing assets to generate sales. The sales is therewith accounted relative to the company size (Chunchi \& Ho, 1997). The work of Tangen (2003) is concerned with the most appropriate measures to use in order to determine the performance that matches the company's situation. He argues that in order to target a "...complete and balanced view of a company..." (Tangen (2003, p. 347)), it is important to select and combine various types of performance measures. To this end, it is suggested to take into account productivity measures that relate the output of a company's activities to the required input. He defined 'profit margin', 'return on sales', 'return on assets' and 'return on equity' as most important indicators. 'Operating margin' (after taxes) as well as 'asset efficiency' are also considered as indicators of business performance (Tangen, 2003, p. 350). Tan and Smyrnios (2011, p. 45) investigated performance measures that are especially useful for fast-growth small-to-medium enterprises. Based on their investigations, they argue that the ratio between number of employees and the turnover can provide useful insights into company performance.

Profitability measures have been the research subject of Gladen (2014) who considers contemporary profitability measures as well as other capital profitability measures. The latter type of measures support the approach of Tan and Smyrnios (2011). Contemporary profitability measures include 'Earnings before Interests and Taxes' (EBIT), 'Earnings before Interests, Taxes, Depreciation \& Amortization' (EBITDA), 'Net-OperatingProfit-after-Taxes' (NOPAT) and 'Economic Value Added' (EVA). Typical capital profitability measures are 'Return on Investment' (RoI), 'Return on Assets' (RoA), and 'Return on Equity' (RoE).

\subsection{Research on the linkage between website quality and corporate performance}

Watkins and Smith (2008) conducted a study about the correlation between website quality and corporate financial performance for 100 listed manufacturing companies in the United Kingdom. In this study usability was considered a significant determinant for the website quality. The following criteria were used in order to determine website quality: learnability, rememberability, efficiency of use, reliability in use and user satisfaction as main factors for determining it. The data about the websites was collected through a special questionnaire that is referred to as a Website Analysis and Measurement Inventory questionnaire (WAMI). The corporate performance was considered in the study through the use of the measures of size (market capitalization), profitability (profit margin), gearing (debt/equity ratio), and liquidity (current ratio). Drawing on the before mentioned determinants, the following four hypotheses were set up: (H1) there is a positive relationship between website quality and company size, (H2) there is a positive relationship between website quality and profitability, (H3) there is an inverse relationship between website quality and financial gearing, (H4) there is a positive relationship between website quality and liquidity. Using the Pearson Correlation Coefficient, the researchers concluded that only hypothesis $\mathrm{H} 3$ can be confirmed providing evidence for an inverse relationship between website quality and financial gearing. The other three hypotheses were refused.

Another research conducted by Masurel (2004)examined whether SME companies with websites can be said to have a better performance than those without websites. However, it appears that the study was concluded with no clear result. Companies which maintain a website grow with almost the same pace as their counterparts without a website. This means that at the time the study was conducted, in 1999, the existence of a website had no impact on the productivity. However, introducing a website very early (early adopters) indicates an overall better performance throughout the following years. Vaughan and Wu (2004) studied the correlation between the link count to a website and the financial performance. They limited their sample to 100 top Chinese IT companies as IT companies are understood as pioneers and specialists in Internet utilization. The inlink data was gathered through manual link searches. As financial indicators they defined gross revenue, profit, export revenue as well as research and development (R\&D) expenditures. The analyses provided evidence for the existence of correlations between link count and gross revenue, profit and R\&D expenses. Vaughan (2004)conducted another study that targeted IT companies in the United States and Canada but without performing a company ranking as in his earlier joined research described before. Furthermore, different countries were taken into account with the aim of investigating whether the outcome of the earlier study was still valid. He concluded that there exists a significant correlation between performance measures (revenue and revenue per employee) and inlinks to the website of a company.

\subsection{Project overview}

The starting point of the study presented in this article is the research project eBusCo.Net (Electronic Business in Company Networks) that was funded in the Interreg IIIa program of the European Union project in the years 2006 to 2008. The project was successfully completed by the two main partners, the University of Applied Sciences Kiel and the University of Southern Denmark and also by support from business development agencies (Rasmussen \& Thimm, 2011). The project team collected data about 500 SME production companies in the 
German Technology Region K.E.R.N (Schleswig-Holstein regional network of regions Kiel, Eckernförde, Rendsburg and Neumünster) and also about 500 SME production companies located in the region of Southern Denmark. Through a postal questionnaire and further interviews, the companies were asked about their degree of networking with partners and the use of information and communication technology (ICT) for the cooperation with partners. Furthermore, also innovative ICT concepts for supporting Virtual Companies were investigated, prototyped, and evaluated. This included, for example, a software tool for moderation management in company networks (Thimm \& Rasmussen, 2010).

The successful completion of the eBusCo.Net project led to several ideas for follow-up research. In the year 2008 researchers from the Pforzheim University and the University of Southern Denmark started to corresponding investigations. In the first phase of this study, it was intended to investigate explanations and the possible motivation of companies for not participating in the original eBusCo.Net questionnaire. To this end, in the year 2009 the homepages of the companies were evaluated based on a set of website quality criteria. The obtained extended data collection about the companies was evaluated in order to reveal if participating and nonparticipating companies differ with respect to the website quality (Rasmussen \& Thimm, 2015). This research eventually led to the question whether there are statistically demonstrable correlations between typical company performance indicators and the dynamics of website quality. To answer this question, the homepages of the companies were revisited and evaluated in the year 2014. The result data of both evaluations were linked to selected company performance indicators of the companies. As data source for these corporate performance indicators we used the ORBIS database, which is offered by the company Bureau van Dijk as a commercial service (Bureau van Dijk, 2015). The ORBIS version ORBIS Europe contains business information and key figures of82 million European companies. The data extraction for the study covered data for a set of 12 indicators concerning the respective companies. The various data that represent annual values for the period from the year 2005 to the year 2014 were linked to the respective data about website quality.

\subsection{Evaluation of website quality and selected company indicators}

In recent decades, several research groups proposed almost 50 different methods to evaluate website quality. An overview of a subset of these methods can be found in Schilling (2015). On the basis of these existing approaches an evaluation method was developed that is tailored to the specific needs of our project (Rasmussen \& Thimm, 2015). In the preceding Section 4.1, an overview of this method is given. This is followed by Section 4.2 which describes the performance indicators that are used in our research.

\subsection{Criteria and method for evaluation of website quality}

The first research phase established a simple but yet sufficient method to evaluate website quality of company websites (Rasmussen \& Thimm, 2015): An evaluator is requested to visually inspect the homepage of a company based on 24 criteria. This may include the use of scroll bars in order to inspect the otherwise hidden bottom part of the homepage. However, the evaluator is instructed to only inspect the homepage and no further pages below.

Table 1 contains the criteria that were used in the website study of the year 2009. The left side of the table contains the criteria concerning the website functionality. The other criteria are directed at evaluating website aesthetics according to popular website design recommendations (Beaird, 2007; McIntire, 2008). All of the 24 criteria were formulated in a way so that the evaluator can choose between 'yes' and 'no' as a qualitative evaluation judgment. The majority of the questions address the existence of common website features (for example, 'Is a login available?'). In order to assure a high quality data collection, the evaluators were instructed to not inadvertently overlook relevant website features. For some of the evaluation criteria, the evaluators were prompted to assess the strength of a feature (for example 'Is the font appropriately small in the general text?'). It is possible that especially the scores on such aesthetic criteria are biased by subjective assessments.

In order to obtain an aggregated evaluation result for each website the number ' 1 'is assigned as score value for positive answers to the criteria1 to 19 . The negative responses to these questions are scored with the number ' 0 ' instead. This assignment is swapped for the reversed questions 20 to 24, i.e. an affirmation was counted with '0' and a negation with ' 1 '. Based on the evaluator's review every existing company website could obtain a website quality score between the maximum score of 24 rating points and the worst score of 0 points.

Table 1: Criteria for the evaluation of website quality

Criteria for Evaluating Website Functionality

1. Does the site have an intro?

2. Is the site in Danish?

3. Is the site in German?

\section{Criteria for Evaluating Website Aesthetics}

17. Is the font appropriately small in the general text?

18. Is the menu in the top of the 
4. Is the site in English?

5. Does the site have a link to customer information?

6. Does the site have a login?

7. Does the site have an online shop?

8. Does the site advertise for subscription of a newsletter?

9. Does the site have a product catalogue?

10. Does the site offer pamphlet ordering?

11. Does the site offer support/download?

12. Does the site contain access to FAQ?

13. Does the site contain access to a blog?

14. Does the site contain access to a chat?

15. Does the site contain news?

16. Is there a search function in the front page? website?

19. Does the site contain pictures?

20. Does the website seem oldfashioned?

21. Are there annoying effects - e.g. animation, sound?

22. Is the website under construction?

23. Does the website have technical problems?

24. Does the front have serifs?

\subsection{Selected company performance indicators}

For many years a growing trend towards an indicator-based business management can be observed that involves traditional indicators (Smith, Skousen, \& Simons, 1984). The constant change in the corporate world has led to continuous proposals of refinements of these existing indicators and also proposals for new indicators. For our study, 12 company performance indicators were selected with the intention to cover a broad spectrum of different business perspectives. The selection includes metrics to measure the capital structure, profitability, productivity, and solvency of companies. In addition, various absolute indicators were taken into account such as the number of employees that is typically used as a measure of the company size. This article has the focuson a subset of the six indicators described in Table 2.

Table 2: The company performance indicators focused in this article.

\section{Performance indicators and Description}

Financial gearing: Measure of the capital structure which indicates financial risks (e.g. bankruptcy, dependence on external financing).

Profit margin: Effectiveness measure. Allows a statement about how much EBIT (operating profit) has been generated for one currency unit turnover.

Employee productivity: Reflects human resource intensity. Allows a statement about how much net income has been generated by one employee.

Return on equity: Measures how efficiently equity is used. It answers the question of how much income has been generated by one currency unit equity.

Current ratio: Ratio of solvency. Measures whether the company is solvent or not.

Number of employees: Absolute measure of company size.

\section{Calculation formula}

Long term liabilities + Current liabilities

Equity

$$
\text { EBIT }
$$

Turnover

Net income

Number of employees

Net income

$\overline{\text { Shareholders'equity }}$

Current assets

$\overline{\text { Current liabilities }}$

Number of employees

\subsection{Country comparison of website quality}

The following comparison of website quality between the Danish SMEs and German SMEs is based on the website evaluation of the year 2009. The most interesting statistical results are presented and discussed in the following. A detailed description of these and other comparison results is available in two Bachelor Theses recently completed at Pforzheim University (Krell, 2015; Schilling, 2015).

The sample of the study included all Danish and German companies that have been considered in the above described initial study of the eBusCo.net project. Out of this set of companies a website could be found for 
$\mathrm{n}=738$ companies. Table 3 contains a summary of the calculated statistical results for website quality in the year 2009. The meaning of the three different quality indicators is as follows. The indicator $Q_{\text {func }}$ refers to the scoring result obtained for the first 16 criteria that are directed at the website functionality. The indicator Qaest refers to the scoring result of the remaining 8 criteria that are directed at measuring the website aesthetics. The overall quality is addressed by the indicator $Q_{\text {total }}$ which corresponds to the sum of the other two scoring results.

Table 3: Statistical results for website quality in of 2009.

$\begin{array}{lrrr}\text { Statistical parameters } & \text { Quality } Q_{\text {func }} & \text { Quality } & \text { Quality } \\ \text { n } & 738 & 738 & 738 \\ \text { Average } & 4,36 & 5,62 & 9,98 \\ \text { 25\%-Percentile } & 3 & 5 & 9 \\ \text { 50\%-Percentile } & 4 & 7 & 11 \\ \text { 75\%-Percentile } & 6 & 7 & 13 \\ \text { Standard deviation } & 2,66 & 2,27 & 4,52 \\ \text { Max } & 13 & 7 & 19 \\ \text { Min } & 0 & 0 & 0\end{array}$

When comparing the obtained mean total website quality of 9.98 with the possible maximum value of 24 it is fair to state that in general a relatively low total website quality was observed in the study. The companies in particular achieve a relative low score of 4.36 out of a maximum of 16 score points with regards to the website functionality. With respect to the website aesthetics the companies achieve a better score of 5.62 out of a maximum of 8 score points. One explanation for this difference could be that the integration of functionality into a website usually requires extensive IT knowledge. Such skills are in SMEs often not available and, therefore, need to be purchased from external consulting companies. The better aesthetic scoring can also be explained by the fact that through website developments kits it is relatively easy to meet major aesthetic requirements. Even people without extensive web design skills can obtain acceptable results with support from proper development kits.

Figure 1: Comparison of website quality between the German and Danish companies.

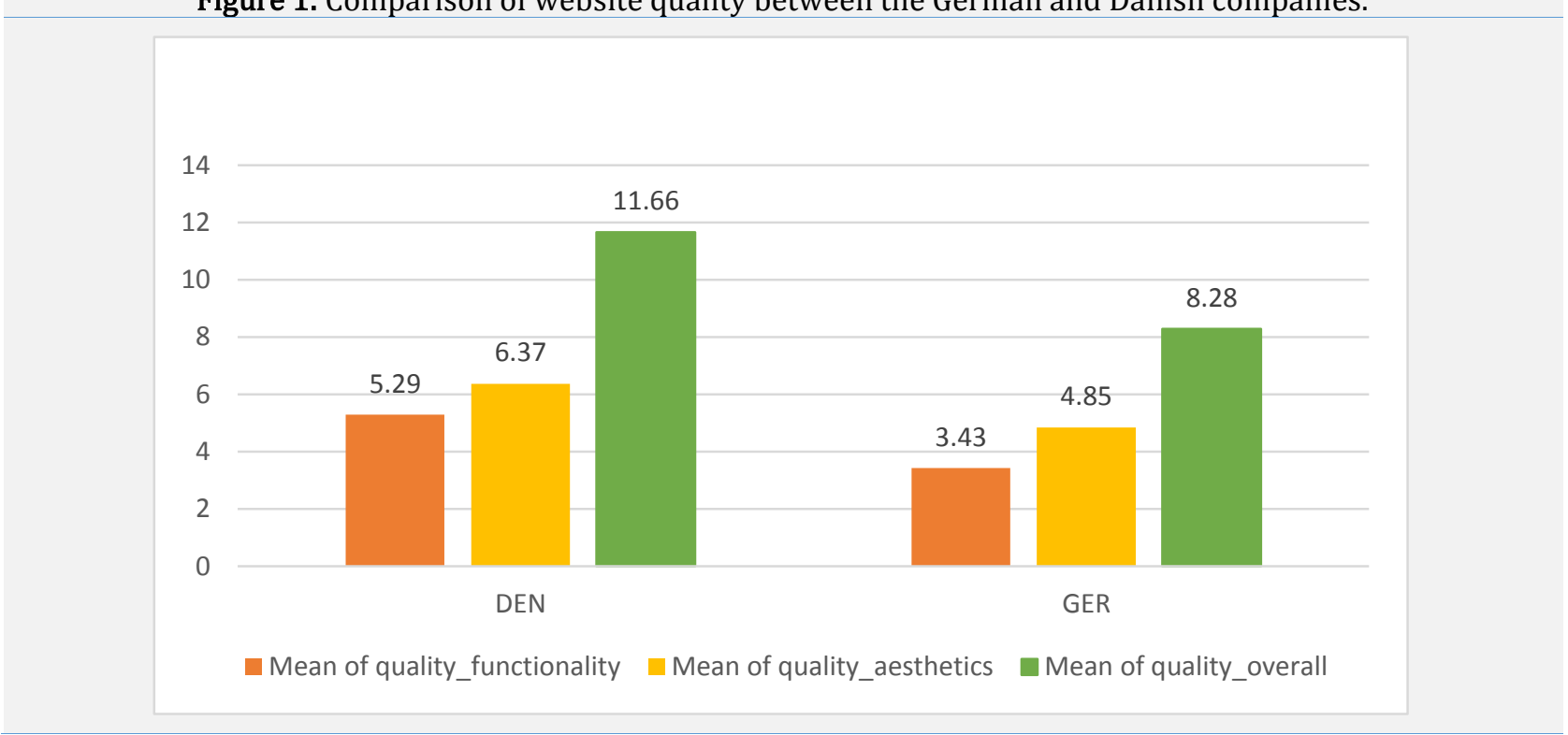

A comparison of the three website quality indicators between the German and Danish companies is given in the histogram of Figure 1. The given numerical values correspond to the respective mean values. The diagram shows that the Danish companies performed better in all three quality indicators than the German companies. A relatively large difference of $11.66-8.28=3.38$ can be observed between the two company groups with respect to the overall quality. It is particularly striking that the German websites with respect to the functional criteria with 3.43 points were evaluated significantly weaker than the Danish websites with 5.29 points. This result suggests that German SME companies compared to Danish SMEs have more difficulties with the integration of functionalities into their company websites. As an alternative to this interpretation, one could state that a high quality website is for Danish companies of greater importance than for German companies. Support for this assumption can be found in comparative international studies of the current digitization status and the IT education status in Europe (European Commission (EU), 2015; Statistica, 2015). In these studies Denmark achieve stop ranks while Germany usually only manages to achieve midfield scores. 


\subsection{Correlation analysis}

It is the general objective of correlation analysis to explore relationships between two or more features that are observed about entities such as companies. In the particular case of the described study these feature data included the website quality as observed in the years 2009 and 2014. Furthermore, the data collection also contained feature data for the selected company performance indicators. Note that these feature data are the actual numbers such as the profit margin of the respective companies for a particular year as extracted from the ORBIS database.

In our study, we focus on various correlation analyses for pairs of features within the data for the year 2009. In general, various graphical and mathematical methods are available in order to explore dependencies and structures in the data collection. Section 6.1 describes the statistical analysis methods considered in our research and their general application. A summary of the calculated statistical results and various interpretation alternatives are given in Section 6.2.

\subsection{Overview of used statistical methods}

Of the various popular methods for a correlation analysis we selected in a first step the Pearson method and the Spearman method for the intended exploration of correlations between the website quality and company performance indicators. These two statistical analysis methods are widely used for a test of correlation between two variables (Specht, Bulander, \& Gohout, 2012). The Spearman method is based on the Pearson method. The Pearson method compares the real data values and is thus usually used for cardinal (i.e. metric) features. As opposed to that, the Spearman method is designed to explore correlations for features with ordinal value characteristics. To this end instead of a comparison of the original data values the Spearman method compares the ranks of the data values. Therefore, in a correlation analysis according to the Spearman method an intermediate step needs to rank the data values that are available for the features (i.e. indicators).

Usually correlation analyses are to be performed with 'non perfect' data sets that refer to observed feature values. Researchers in these analyses frequently face measurement errors, 'missing values', and other data collection problems. A common approach to deal with these problems in correlation analyses for variable pairs is to exclude 'outlier data pairs' that are caused by these problems. Therefore, it is expected for descriptions of correlation results to indicate the precise number of considered data pairs. In the following the requirements and principles of both methods for correlation analyses are further introduced. Note that we use the notion of 'variable' as a synonym for 'feature' as it is common in the statistic literature.

The Pearson correlation analysis in general examines whether a linear correlation exists between the two variables. To this end the Pearson correlation coefficient $R_{p}$ is calculated from the available data set. However, the Pearson method only provides test statements in the sense of the statistical inference when a bivariate normal distribution is found for the pair of variables, i.e. when the set of data pairs are bivariate normally distributed. It is possible to test this condition for example with the test of (Hanusz \& Tarasinska, 2014).

In comparison to the Pearson method, the Spearman method is based on a broader interpretation of the concept of mutual relationship between two variables. The Spearman method looks at ranks of the data values as opposed to the data values themselves and calculates the Spearman rank correlation coefficient $R_{\text {sp. }}$ The calculation method does not require the existence of a bivariate normal distribution of the variables. Thus, when it is not possible to use the Pearson method due to the absence of a bivariate normal distribution of the variable pair one can use the less restrictive alternative Spearman method.

Figure 2: Scatterplot for the indicator pair number of employees and website quality. 


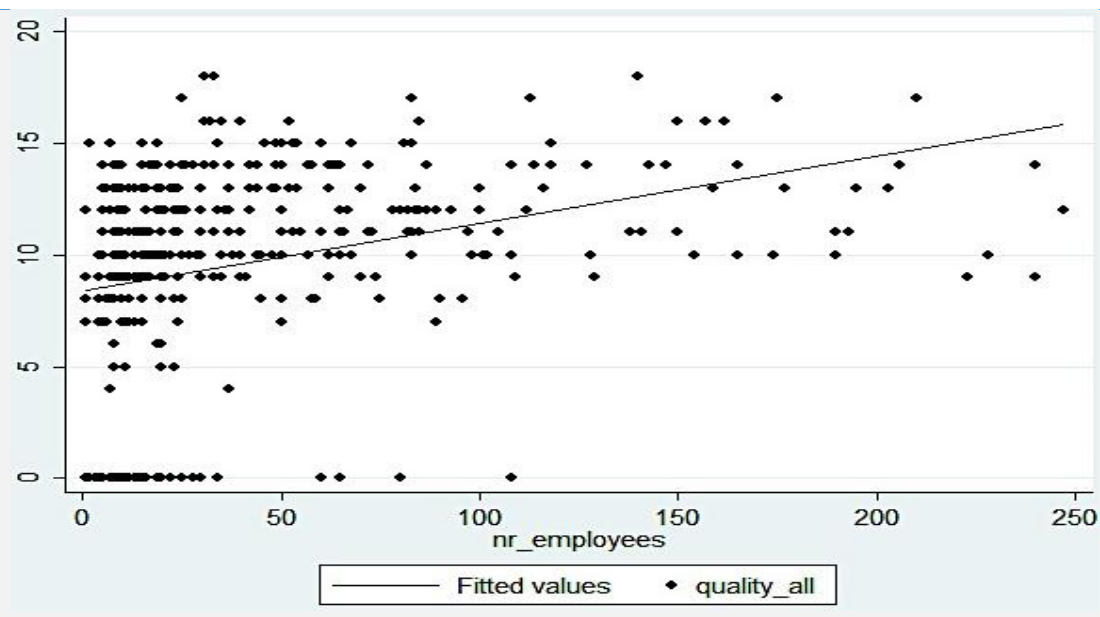

The diagram of Figure 2 shows the scatter plot of the variable pair 'website quality/number of employees' as obtained from the data set. The graphical visualization of the sample as a scatter plot - each point corresponds to a value pair - in correlation analyses often serves for an initial review of suspected correlations between the variables. In many cases, it is possible to obtain first clues about the correlation from the graph such as the direction, shape, and strength of the correlation.

Recall from above that of the original set of about 1000 companies considered, in the year 2009 websites for only 738 companies were found. From the data subset of these 738 companies a subset of 406 companies was extracted where a corresponding value for both the indicator 'website quality' and the indicator 'number of employees' was available. The scatter plot shows the corresponding set of 406 data pairs that served as a basis for the further steps towards correlation results. The 94 data points positioned directly on the abscissa correspond to companies whose website was evaluated with a minimum quality score of 0 . After the exclusion of 'outliers' and of further data pairs that are discussed in the next section in more detail, a total of $\mathrm{n}=368$ pairs could be used for the targeted correlation analysis. For these $n=368$ data pairs a corresponding test proved this set of data pairs of the indicator pair 'website quality / number of employees' to be normally distributed.

For the indicator pairs 'website quality / profit margin', 'website quality / employee productivity' and 'website quality / current ratio' a bivariate normal distribution was also obtained after excluding 'outlier data pairs'. Therefore, for these indicator pairs the investigation of correlations could proceed by applying the Pearson method.

For other indicator pairs it was not possible to obtain bivariate normal distributions through the exclusion of outliers. Consequently, the Spearman method was used in order to investigate correlations for the indicator pairs 'website quality / financial gearing' and 'website quality / return on equity'.

\subsection{Correlation analyses for website quality and corporate performance indicators}

Table 4 gives an overview of the correlation values that we calculated from the data of the year 2009. Following usual denotation conventions in the table the number of considered data pairs is denoted by $n$. The labels $R_{s p}$ and $\mathrm{R}_{\mathrm{p}}$ denote the Spearman rank correlation coefficient and the Pearson correlation coefficient, respectively. The empirical significance level is denoted by $\mathrm{p}$. The interpretations used in this article are defined in Table 5 and Table 6.

As given in Table 4, statistically significant relationships are only obtained for the three indicator pairs 'website quality / financial gearing', 'website quality / number of employees', and 'website quality / return on equity'. In the following, these results are discussed including interpretations from a statistical perspective. However, the discussion does not address indicator pairs for which non-significant correlations were found.

Table 4: Results of the correlation analysis of the various indicator pairs.

$\begin{array}{rrrrrr}\text { Profit } & \text { Employee } & \text { Current } & \text { Financial } & \text { Number of } & \text { Return on } \\ \text { Margin } & \text { productivity } & \text { ratio } & \text { gearing } & \text { employees } & \text { Equity }\end{array}$




\begin{tabular}{|c|c|c|c|c|c|c|}
\hline \multirow[t]{3}{*}{ Website Quality } & $\mathrm{n}=72 \mathrm{R}_{\mathrm{p}}=$ & $\mathrm{n}=72$ & $\mathrm{n}=262$ & $\mathrm{n}=515$ & $n=368$ & $\mathrm{n}=294$ \\
\hline & 0.0582 & $\mathrm{R}_{\mathrm{p}}=0.0228$ & $R_{p}=-$ & & & \\
\hline & $p=0.3136$ & $\mathrm{p}=0.4245$ & $\mathrm{p}=\begin{array}{r}0.0214 \\
0.6351\end{array}$ & $\begin{aligned} R_{s p} & =0.0774 \\
p & =0.0396\end{aligned}$ & $\begin{aligned} R_{s p} & =0.4004 \\
p & =0.0000\end{aligned}$ & $\begin{array}{r}\mathrm{R}_{s p}= \\
0.1298\end{array}$ \\
\hline $\begin{array}{l}\text { Interpretation } \\
\text { correlation }\end{array}$ & very weak & very weak & $\begin{array}{r}\text { negative } \\
\text { and very } \\
\text { weak }\end{array}$ & very weak & $\begin{array}{r}\text { mediumcorrela } \\
\text { tion }\end{array}$ & $\begin{array}{l}p=0.0131 \\
\text { very weak }\end{array}$ \\
\hline $\begin{array}{l}\text { Interpretation } \\
\text { significance level }\end{array}$ & $\begin{array}{r}\text { not } \\
\text { significant }\end{array}$ & $\begin{array}{r}\text { not } \\
\text { significant }\end{array}$ & $\begin{array}{r}\text { not } \\
\text { significant }\end{array}$ & significant & $\begin{array}{r}\text { highly } \\
\text { significant }\end{array}$ & significant \\
\hline
\end{tabular}

Table 5: Interpretation of the correlation coefficient.

\begin{tabular}{ll}
\hline Correlation coefficient & Possible interpretation \\
$\mathrm{R}=0$ & No correlation \\
$0<|\mathrm{R}| \leq 0.2$ & Very weak correlation \\
$0.2<|\mathrm{R}| \leq 0.4$ & weakcorrelation \\
$0.4<|\mathrm{R}| \leq 0.6$ & Medium correlation \\
$0.6<|\mathrm{R}| \leq 0.8$ & Strong correlation \\
$0.8<|\mathrm{R}|<1$ & Very strong correlation \\
$|\mathrm{R}|=1$ & Perfect correlation \\
\hline
\end{tabular}

Table 6: Interpretation of empirical significance levels.

$\begin{array}{ll}\text { Empirical significance level } & \text { Possible interpretation } \\ 0.1 \leq \mathrm{p} & \text { Not significant } \\ 0.05 \leq \mathrm{p}<0.1 & \text { Weakly significant } \\ 0.01 \leq \mathrm{p}<0.05 & \text { significant } \\ \mathrm{p}<0.01 & \text { Highly significant }\end{array}$

For the pair 'website quality / financial gearing' after excluding missing values the correlation analysis could be completed with $\mathrm{n}=515$ data pairs. The exclusion of corresponding outlier data pairs for 'website quality / number of employees' leads to a set of $n=368$ data pairs. The lower number of data pairs is caused by the need to exclude companies with more than 249 employees that according to European Union's SME definition may not be considered as small and medium sized enterprises. Furthermore, companies were excluded for which in the ORBIS database rather than an absolute number of employees only a magnitude indication was available (for example, $<150$ employees). Likewise, companies were excluded with a website quality score of 0 . For the indicator pair 'website quality / return on equity' the correlation test could be performed with $\mathrm{n}=294$ data pairs. The relatively low number of data pairs results from the restriction to only consider companies with a return on equity between -0.3 and 0.5 while excluding all other data pairs as 'outliers'.

The analysis results obtained for 'website quality / financial gearing' indicate that just a significant positive rank correlation exists $(0.01 \leq \mathrm{p}<0.05$ fulfilled) between the website quality of companies and the financial gearing of companies. The rank correlation coefficient with a value of around 0.08 signifies a very weak correlation.

It is just possible to give a very limited interpretation of these analysis results. The main reason for this limitation results from fact that the financial gearing is a ratio number that relates the company's liabilities (i.e. long-term liabilities + current liabilities) to the company's equity. For example, a high financial gearing is obtained when the liabilities are of a high value and at the same time the equity is of a low value. According to the statistical test results, such a situation - that is the existence of a strong financial gearing - will be accompanied by a high quality company website. That companies are likely to invest in a relatively high quality website in particular when their liabilities are high may seem to be a surprising result. However, one can find plausible arguments for this correlation. For example, one can assume that through a good website quality companies especially intend to maintain trust with existing creditors and with potential new creditors. Conversely, when the liabilities are relatively low then the company may feel less prompted to invest into trust building measures such as a high quality company website.

According to the analysis results, there exists a highly significant ( $p<0.01$ fulfilled) positive rank correlation between the website quality and the number of employees. One can describe the strength of the correlation with a rank correlation coefficient of around 0.4 to be moderate $\left(0.4<\mathrm{R}_{\mathrm{sp}} \leq 0.6 \mathrm{fulfilled}\right)$. Of the various possibilities for an interpretation of these analysis results only two shall be described in the following. A growing importance of the website quality that parallels the growth of the number of employees can be related to the 
growth impact of the company. Especially, with more employees being hired also the volume of required information exchange, communication, and coordination will go up. It is possible to address this increase of the mentioned volumes by a website that offers built-in communication and coordination functionalities. This is why a company's ongoing growth may increasingly boost the motivation to provide a high quality website. As compared to a low quality website when the company website is of a high quality then for the employees it is easier to find and access the information needed for their tasks. This may possibly contribute to a good employee productivity. However, as described above the investigations based on the available data collection did not confirm the existence of a significant positive correlation between the website quality and employee productivity.

The observation of a better website quality for companies with larger number of employees can also be explained by the fact that a well-designed website is especially beneficial for attracting new employees. In other words, one can assume that the website quality of a company is likely to improve with increasing number of employees. It is intended to test this assumption by a future correlation analysis between the increase of number of employees and the increase of website quality.

Similar to the indicator 'financial gearing' also the indicator 'return on equity' is a ratio number. Therefore, the correlation analysis results for 'website quality / return on equity' only allow a very limited interpretation. For this reason, a deliberately stint discussion of these results is given in the following. The calculated rank correlation coefficient with a value of around $R_{s p}=0.13$ corresponds to only a very weak correlation which is however statistically significant $(0.01 \leq \mathrm{p}<0.05$ fulfilled). When a high return on equity can be observed for a given company then the company is likely to also have a high quality website. This interpretation of the test result appears to be plausible. One can assume that profitable companies will exploit the existing financial flexibility by establishing an investment portfolio that among others targets a high quality website.

\subsection{Analysis of correlations between the constituent parts of ratio number financial gearing and website quality}

In general, bivariate correlation analyses can involve indicators that are absolute numbers like the number of employees. But it can also be required to perform correlation analyses with indicators that are ratio numbers like the indicator 'financial gearing' and the indicator 'profit margin' as demonstrated in the previous section. When one or both of the indicators are ratio numbers then the correlation analyses leads to results which are difficult to interpret. In the following, this problem is further investigated based on the indicator pair 'website quality/financial gearing'.

As described in Section 4.2, the financial gearing is calculated as the ratio of the sum of long-term liabilities and current liabilities as numerator and the equity as the denominator. Consequently, a high value of financial gearing is obtained when the total liabilities are of a high value in comparison to the value of the equity. Recall from the evidence described in Section 6.2 that for companies with a high value of financial gearing one can expect the website of the company to be of a high quality, too. The aforementioned interpretation of theanalysis result for 'website quality / financial gearing' seems to be plausible.

Even if a plausible explanation for an obtained analysis result can be found one may still be interested in further insights into the correlations of indictor pairs that include ratio numbers. In order to add further insight to the results of an initial correlation analysis, a further two-step analysis approach can be helpful. In a first step the ratio number(s)is/are decomposed into the respective constituent parts, i.e. components according to the ratio number's formula. Then in a second step the correlations between the resulting components and the second indicator can be explored.

Following the two-step approach described above a set of corresponding correlation analyses was performed for the indicator pair 'website quality / financial gearing'. The results of these correlation analyses are contained in Table 7. In addition, the table also includes the results of correlation analyses for the constituent parts of the ratio number 'financial gearing' and the indicator 'number of employees'. The correlation results are based on the use of the Spearman method.

Table 7: Results of bivariate correlation analyses between constituent components of ratio number 'financial gearing' and other indicators.

\begin{tabular}{llllll}
\hline & $\begin{array}{l}\text { Number } \\
\text { employees }\end{array}$ & Equity & $\begin{array}{l}\text { Long-term } \\
\text { liabilities }\end{array}$ & Current liabilities & Financial Gearing \\
\hline $\begin{array}{l}\text { Website } \\
\text { Quality }\end{array}$ & $\mathrm{n}=368$ & $\mathrm{n}=515$ & $\mathrm{n}=515$ & $\mathrm{n}=515$ & $\mathrm{n}=515$ \\
$\mathrm{R}$ & $\mathrm{R}_{\mathrm{sp}}=0.4004$ & $\mathrm{R}_{\mathrm{sp}}=0.3941$ & $\mathrm{R}_{\mathrm{sp}}=0.3009$ & $\mathrm{R}_{\mathrm{sp}}=0.4228$ & $\mathrm{R}_{\mathrm{sp}}=0.0774$ \\
\hline
\end{tabular}




\begin{tabular}{|c|c|c|c|c|c|}
\hline & $\mathrm{p}=0.0000$ & $p=0.0000$ & $p=0.0000$ & $\mathrm{p}=0.0000$ & $p=0.0396$ \\
\hline \multirow{3}{*}{$\begin{array}{l}\text { Number of } \\
\text { employees }\end{array}$} & & $n=368$ & $n=368$ & $n=368$ & $n=368$ \\
\hline & & $\mathrm{R}_{\mathrm{sp}}=0.5497$ & $\mathrm{R}_{\mathrm{sp}}=0.5792$ & $\mathrm{R}_{\mathrm{sp}}=0.4580$ & $\mathrm{R}_{\mathrm{sp}}=0.0583$ \\
\hline & & $\mathrm{p}=0.0000$ & $\mathrm{p}=0.0000$ & $\mathrm{p}=0.0000$ & $p=0.1325$ \\
\hline \multirow[t]{3}{*}{ Equity } & & & $\mathrm{n}=515$ & $\mathrm{n}=515$ & $\mathrm{n}=515$ \\
\hline & & & $\mathrm{R}_{\mathrm{sp}}=0.4415$ & $\mathrm{R}_{\mathrm{sp}}=0.6122$ & $\mathrm{R}_{\mathrm{sp}}=0.0874$ \\
\hline & & & $\mathrm{p}=0.0000$ & $p=0.0000$ & $\mathrm{p}=0.0240$ \\
\hline Long-term & & & & $\mathrm{n}=515$ & $\mathrm{n}=515$ \\
\hline liabilities & & & & $\mathrm{R}_{\mathrm{sp}}=0.4243$ & $\mathrm{R}_{\mathrm{sp}}=0.2012$ \\
\hline & & & & $\mathrm{p}=0.0000$ & $\mathrm{p}=0.0000$ \\
\hline Current & & & & & $\mathrm{n}=515$ \\
\hline liabilities & & & & & $\mathrm{R}_{\mathrm{sp}}=0.1388$ \\
\hline & & & & & $p=0.0009$ \\
\hline
\end{tabular}

The correlation values in Table 7 show that there exist monotone correlations for all possible pairs of the constituent parts of financial gearing (grey cells in Table 7). The level of the obtained correlations range from about a medium value $\left(0.4<\mathrm{R}_{\mathrm{sp}} \leq 0.6\right.$ fulfilled) to an about strong value $\left(0.6<\mathrm{R}_{\mathrm{sp}} \leq 0.8\right.$ fulfilled). It is an interesting result that the correlations are of high statistical significance ( $p<0.01$ fulfilled). Of all considered indicator pairs the highly significant correlation between the equity and the current liabilities is the most significant one with $\mathrm{R}_{\mathrm{sp}}=0.6122$. This result suggests that in practice a high amount of equity goes hand in hand with a high amount of current liabilities. This seems to be plausible insofar as current liabilities are easier to obtain whenthe company is able to provide evidence for a high value of equity.

The results of the correlation analysis between the website quality, the number of employees, and the components of financial gearing (yellow marked cells) can be described as follows. For the indicator pair 'current liabilities / website quality' positive statistically highly significant ( $p<0.01$ fulfilled) monotonic correlation was obtained. The levelof this correlation is of a medium strong value $\left(R_{s p}=0.4228\right)$. This result suggests that the greater the current liabilities the higher the website quality and vice versa. The same applies to the indicatorpair'current liabilities / number of employees'. However, with $R_{s p}=0.4580$ the level of this indicator pair is of a slightly weaker value as the former pair.

For the indicator pair 'long-term liabilities / website quality' a highly significant positive monotonic correlationis determined. However the level of this correlation is rather weak $\left(\mathrm{R}_{\mathrm{sp}}=0.3009\right)$. An interpretation of this finding is as follows. The greater the long-term liabilities the higher the website quality and vice versa. The indicator pair 'long-term liabilities / number of employees' shows a high statistical significance with a moderately high correlation coefficient of $\mathrm{R}_{\mathrm{sp}}=0.5792$.

The indicator pair 'equity / website quality' has a highly significant positive monotonic correlation. With a correlation coefficient of $\mathrm{R}_{\mathrm{sp}}=0.3941$ the level of the correlation is relatively weak which can be interpreted as follows. The greater the equity the higher the website quality and vice versa. The same statement also holds true for the correlation between the equity and the number of employees except for the level of the correlation. The correlation coefficient obtained for this pair with $\mathrm{R}_{\mathrm{sp}}=0.5497$ signifies an about medium strong correlation level.

The correlation values confirm the obvious assumption that the website quality of a company is linked to the financial resources of a company. As the company has more equity available the more likely it is that the construction, the development and maintenance of the corporate website is performed by adequately qualified people. One can assume that financial leeway, that usually exists in well financed companies, will be used for the purchase of external consulting services and / or for web design trainings for employees. That an existing financial leeway is actually used for investments in such measures, however requires a corresponding willingness to invest and also a general interest in innovation. A willingness to invest in a high-quality website will most likely only be available when the company regards this as a worthwhile investment. When a good capital base is available then it is most likely easier for company-internal promoters for website projects to get a good share of the company's investment budget.

As confirmed by the correlation values in Table 7 there exists a highly significant correlation between every constituent part of the indicator 'financial gearing' and the website quality. When calculating the financial gearing according to the formula with these individual components, however, then the correlation between the financial gearing and the website quality becomes less important. This apparently is a result of a superposition of the correlations which occurs when the financial gearing is calculated by the given ratio number formula. 


\subsection{Conclusion and outlook}

The statistical analyses of the data collection lead to new insights into the importance of a high quality website for Danish and for German SME manufacturing companies. One of the findings is that Danish companies have a higher score than German companies with respect to the website quality. The study also shows a positive correlation between the website quality and the number of employees. Also, a correlation was found for the indicator pair 'website quality / financial gearing'. The results of a bivariate correlation analysis proved this correlation to be insignificant for the practice. However, a different result emerges when the ratio number 'financial gearing' is decomposed into its constituent parts followed by correlation analyses. Between the constituent parts of the indicator 'financial gearing' - that is the indicators 'long-term liabilities', 'current liabilities', and 'equity' - and the website quality highly significant correlations are obtained. For the indicators 'profit margin', 'employee productivity', 'return on equity', and 'current ratio', which are also ratio numbers, the correlation analyses yield sufficient evidence for the existence of correlations with the website quality.

The results of the study may prove helpful for various players including regional development organizations and policy makers. The different website quality scores in the two investigated adjacent regions may prompt business development agencies in the regions to initiate website quality improvement programs especially for SME companies. Furthermore, the evidence for the highly significant correlations can be used by local policy makers in order to initiate SME specific financial support programs for website development and improvement.

The statistical analyses also lead to various new questions concerning possible explanations, interpretations, and other aspects of the results. At present, we are conducting further statistical analyses in order to answer these questions. In the future, we will also investigate the qualitative development of the investigated websites and the economic enterprise development in the period from the first evaluation in the year 2009 until the second evaluation in the year 2014.

The survey in the year 2014 is extended by additional evaluation criteria such as whether the homepage contains social media links or labels. In particular, the examination of the websites is directed at the quality management label ISO 9000 (Sharma, 2005) and the environmental management label EMAS (Recher, Tschulik, \& Martinuzzi, 2002). This additional data collection will be used to study the correlations between the website quality and special business characteristics. For example, we will investigate, what influence a great openness to the Internet as a sales and marketing medium will have on the website quality of the company. The study will also analyse whether correlations exist between the innovation attitude of enterprises and the website quality. Furthermore, the future research also targets to analyse the correlation between the innovation attitude of companies and the orientation towards sustainability.

\section{References}

Beaird. (2007). The Principles of Beautiful Web Design. Sitepoint. Sitepoint.

Bureau van Dijk. (2015, July). orbis - company information around the globe. Retrieved from http://www.bvdinfo.com/de-de/about-us/brochure-library/brochures/orbis

Chang, K., Chen, M.-C., Hsu, C.-L., \& Kuo, N.-T. (2012). Integrating loss aversion into a technology acceptance model to assess the relationship between website quality and website user's behavioural intentions. Total Quality Management \& Business Excellence, 23(7/8), pp. 913-930.

Cheung, W. M., \& Huang, W. (2002). An investigation of commercial usage of the World Wide Web: a picture from Singapore. International Journal of Information Management, 22(5).

Chunchi, W., \& Ho, S. J. (1997). Financial Ratio Adjustment: Industry-Wide Effects or Strategic Management. Review of Quantitative Finance \& Accounting, 9(1), pp. 71-88.

European Commission (EU). (2015). Digital Agenda for Europe, Digital Economy and Society Index (DESI). Von digital-agenda-data: http://digital-agenda-data.eu/datasets/desi/visualizations abgerufen

Ford, E. W., Huerta, T. R., Diana, M. L., Kazley, A. S., \& Menachemi, N. (2013). Patient Satisfaction Scores and Their Relationship to Hospital Website Quality Measures. Health Marketing Quaterly, 30(4), pp. 334-348.

George, G., Zahra, S. A., \& Wood, D. R. (2002). The effects of business-university alliances on innovative output and financial performance: a study of publicly traded biotechnology companies. Journal of Business Venturing, 17(6).

Gladen, W. (2014). Performance Measurement : Controlling mit Kennzahlen. Springer. 
Gonzalez, F. J., \& Palacios, T. M. (2004). Quantitative evaluation of commercial web sites: An empirical study of Spanish firms. International Journal of Information Management, 24(4), pp. 313-328.

Gregg, D. G., \& Walczak, S. (2010). The relationship between website quality, trust and price premiums at online auctions. Electronic Commerce Research, 10(1), pp. 1-25.

Hanusz, Z., \& Tarasinska, J. (2014). On multivariate normality tests using skewness and kurtosis. Colloquium Biometricum. Colloquium Biometricum, 44, pp. 139-148.

Hernandez, B., Jimenez, J., \& Martin, M. J. (2009). Key website factors in e-business strategy. International Journal of Information Management, 29(5), pp. 362-371.

Hsiu-Fen, L. (2007). The Impact of Website Quality Dimensions on Customer Satisfaction in the B2C Ecommerce Context. Total Quality Management \& Business Excellence, 18(4), pp. 363-378.

Hung-Chang, C., Yi-Ching, H., \& Ching-Yi, K. (2005). Website quality and customer's behavioural intention: an exploratory study of the role of information asymmetry. Total Quality Management \& Business Excellence, 16(2), pp. 185-197.

Hur, Y., Jae Ko, Y., \& Valacich, J. (2011). A Structural Model of the Relationships Between Sport Website Quality, E-Satisfaction, and E-Loyalty. Journal of Sport Management, 25(5), pp. 458-473.

Kaplan, R. S., \& Norton, D. P. (1992). The Balanced Score Card - Measures That Drive Performance. Harward Business Review, pp. 71-79.

Kaya, T., \& Kahramann, C. (2011). A Fuzzy Approach to E-Banking Website Quality Assessment Based on an Integrated Ahp-Electre. E-Bankininkystės Tinklapiu Kokybès Vertinimas Paremtas Integruotu Neapibrėžtuju Aibiu Ahp-Electre Metodu., 17(2), pp. 313-334.

Krell, K. (2015). Krell, K.: Empirical Data Analysis of SME Companies in two adjoining European Regions on Website Quality and Company Development, Bachelor Thesis. Pforzheim: Pforzheim University.

Masurel, E. (2004). Websites and SMEs: do they have productivity impact. International Journal od Entrepreneurship \& Innovation Management, 4(1).

McIntire. (2008). Visual Design for the Modern Web. Berkely, CA: New Riders.

Merritt, C. (2015). Net Sales or Revenue Vs. Net Income. Abgerufen am 1. July 2015 von from http://smallbusiness.chron.com/net-sales-revenue-vs-net-income-59947.html

Miller, S. (2015). Unternehmenskennzahlen - Bewertung der Unternehmensperformance durch Kennzahlen.Retrieved June 5, 2015, from http://www.onlineartikel.de/article/unternehmenskennzahlen-bewertung-der-unternehmensperformance-durchkennzahlen-55473-1.html

Rasmussen, K. B., \& Thimm, H. H. (2011, June). SMEs Experience of Collaboration and their IT Maturity. Proc. 10th European Conference on Research Methodology for Business and Management Studies, Caen, France, pp. 435-444.

Rasmussen, K. B., \& Thimm, H. H. (2015). Circumventing Nonresponse - Upgrading Traditional Company Survey Data with Unobtrusive Data from Company Web Sites. Bulletin of Sociological Methodology, SAGE, Vol. 127, pp. 85-96.

Recher, A., Tschulik, A., \& Martinuzzi, A. (2002). EMAS - an Instrument for Environmental Communication (Examining EMS-evaluation Studies). Proceedings 16th Conf. Envirolnfo, Environmental Communication in the Information Society, Wien, pp. 387-395.

Rosenfeld, L., \& Morville, P. (2002). Information Architecture for the World Wide Web (second edition). Sebastopol, CA: O'Reilly.

Schilling, C. (2015). Schilling, C.: Website Quality and Company Development - Investigations of Empirical Data of German and Danish SME Companies, Bachelor Thesis. Pforzheim: Pforzheim University.

Sharma, D. (2005). The association between ISO 9000 certification and financial performance. The International Journal of Accounting, 40(2), p. 151.

Sierpinska, M., \& Jachna, T. (2004). Ocena przedsię biorstwa według standardo'w s' wiatowych. Warszawa, Poland: Wydawnictwo Naukowe PWN.

Smith, J., Skousen, F., \& Simons, H. (1984). Intermediate Accounting, 9 Edition. Cincinnati, OH: Thomson South-Western.

Specht, K., Bulander, R., \& Gohout, W. (2012). Statistik für Wirtschaft und Technik. De Gruyter Oldenbourg.

Statistica. (2015, Dezember 20). Anteil der Internetnutzer in der Europäischen Union (EU-28) nach Ländern im Jahr 2015. Retrieved from 
http://de.statista.com/statistik/daten/studie/184636/umfrage/internetreichweite-anteil-dernutzer-in-europa/

Tan, C. S., \& Smyrnios, K. X. (2011). HOW DO AUSTRALIAN FAST-GROWTH SMALL-TO-MEDIUM ENTERPRISES MEASURE PERFORMANCE? Journal od Enterprise Culture, 19(1), pp. 41-60.

Tangen, S. (2003). An overview of frequently used performance measures. Work Study, 52(7), pp. 347-354.

Thimm, H., \& Rasmussen, K. B. (2010). A Decision and Transparency Support Service for Moderation Management of Virtual Enterprises in Collaborative Networks. 43rd Hawaii International Conference on System Sciences (HICSS43). IEEE Press.

Vaughan, L. (2004). Exploring website features for business information. Scientometrics, 61(3), pp. 467-477.

Vaughan, L., \& Wu, G. (2004). Links to commercial websites as a source of business information. Scientometrics, 60(3), pp. 487-496.

Watkins, P., \& Smith, M. (2008). Website Quality and Corporate Financial Performance. Journal of Accounting, Business \& Management, 15(1), pp. 71-89.

Xi, Y., Zhuang, Y., Huang, W., She, C., \& Zhang, Z. (2007). The Quality Assessment and Content Analysis of Corporate Websites in China: An Empirical Study. International Journal of Information Technology \& Decision Making, 6(2), pp. 389-405. 